Erwan L'Her

\title{
Is the noninvasive ventilatory mode of importance during cardiogenic pulmonary edema?
}

Received: 28 October 2010

Accepted: 7 November 2010

Published online: 7 December 2010

(C) Copyright jointly held by Springer and ESICM 2010

This editorial refers to the article available at:

doi:10.1007/s00134-010-2082-3.

E. L'Her

CESIM-LATIM INSERM U650, Université de Bretagne

Occidentale, Brest, France

\section{E. L'Her (『)}

Urgences Adultes et Réanimation Médicale,

Pôle Urgences-SAMU, CHU de la Cavale Blanche,

CHU de Brest, 29609 Brest Cedex, France

e-mail: erwan.lher@chu-brest.fr

Tel.: +33-2-98347181

Fax: +33-2-98347965

E. L'Her

Réanimation Médicale, Pôle Vasculaire,

CHU de Brest, Brest, France

Despite its high incidence [1,2] and a high mortality rate after a first episode $(20-40 \%)$ [3, 4], cardiogenic pulmonary edema (CPE) treatment has changed very little during the past 35 years, the only real novelties coming from the proposal for nitrate boluses and the introduction of noninvasive ventilation (NIV). NIV is now routinely used during the emergency care of patients with acute CPE, with the aim of rapidly improving acute respiratory distress symptoms and reducing the need for endotracheal intubation [5]. Several meta-analyses and consensus have positioned the early use of NIV during CPE [6-10], at least in the case of persistent respiratory distress after an adequate medical treatment failure. In such indications, NIV is presumed to reduce by half the intubation and early mortality rates, and was also suggested to be associated with decreased ICU length of stay and hospital costs.
$\mathrm{CPE}$ is the clinical consequence of increased extravascular lung water, itself responsible for reduced lung volumes, compliance, and increased airway resistances by interstitial bronchial edema [11-14]. In response to such physiologic changes, inspiratory muscle load is elevated that in turn generates significant pleural pressure depression. These large pleural pressure swings are responsible for hemodynamic modifications, via an increase of left ventricular afterload and myocardial transmural pressure $[15,16]$. A concomitant impairment in cardiac index in the case of systolic heart failure is likely to decrease oxygen delivery to tissues, particularly within respiratory muscles, thus creating a vicious circle.

Acute hypercapnia is frequently observed in the clinical field [17, 18], especially in elderly patients [3], by the combination of respiratory exhaustion and underlying bronchopulmonary diseases. Therefore, at least from a physiological point of view, the best NIV mode should aim to improve clinical signs of respiratory distress, to decrease the inspiratory muscles' workload, and to improve hemodynamics.

Continuous positive airway pressure (CPAP) is not a new therapeutic issue! By the early twentieth century evidence showed that the application of a positive pulmonary pressure to a patient experiencing acute cardiac failure allowed hemodynamic and respiratory mechanics improvements, while improving clinical signs of respiratory distress [1921]. The effectiveness of CPAP plus medical treatment was compared with that of medical treatment alone by Bersten et al. [17] in a randomized study of 39 hypoxemic patients with respiratory exhaustion (mean $\mathrm{PaCO}_{2} \sim 60 \mathrm{mmHg}$ ). Those authors observed a more rapid improvement of oxygenation under CPAP, associated with a rapid $\mathrm{PaCO}_{2}$ decrease, as compared to control. No patient required the use of endotracheal intubation in the CPAP arm, whereas $35 \%$ of patients in the control group were intubated within $3 \mathrm{~h}$ of enrollment. Similar clinical and biological benefits, associated with a drastic decrease of the 48-h mortality rate, were 
observed in an emergency room multicenter study of elderly patients with severe alveolar hypoventilation [3]. These results were observed and confirmed in various other clinical studies [7-10].

Noninvasive positive pressure ventilation (NIPPSV) can be considered the addition of an inspiratory support to CPAP. Several physiological studies have evidenced in various pathological situations (sub-acute COPD exacerbations, hypoxemic respiratory distress, stabilized CPE) that while CPAP alone was able to reduce the work of breathing (WOB), this effect was greater under NIPPSV [22-24]. NIPPSV also proved superior to CPAP in terms of dyspnea relief [23].

In a first randomized controlled trial comparing CPAP with NIPPSV for CPE, Mehta et al. [25] pointed out a greater improvement of most clinical, biological parameters, and dyspnea reduction under NIPPSV, whereas only the respiratory rate and oxygenation were improved under CPAP. This study induced several interrogations due to its premature termination given the high rate of myocardial infarction in the NIPPSV arm. The fact that these myocardial infarcts preceded inclusion or were the direct result of the ventilator mode was questioned. In a subsequent randomized study, Bellone et al. [26], however, concluded that CPAP and NIPPSV were equivalent in terms of clinical parameters improvement, but also in terms of myocardial infarction rate or troponin plasma levels increase. In all subsequent clinical comparisons, both CPAP and NIPPSV proved superior to medical therapy alone in terms of reducing the intubation rate [27, 28], without any adverse event rate or outcome differences.

A recent randomized trial comparing CPAP, NIPPSV, and standard oxygen therapy in 1,069 patients with acute cardiogenic pulmonary edema raised an important controversy while it demonstrated no mortality benefit from emergent NIV [29]. However, as clearly stated by the authors within their discussion, NIV (whatever its mode of application) allowed rapid improvements in patients' symptomatology and oxygenation parameters at the early phase of treatment, which by itself may be sufficient to justify such a treatment.

In this issue of intensive care medicine, Nouira and colleagues [30] reported the results of another prospective, multicenter, randomized trial comparing the use of NIPPSV versus CPAP during the emergency care of CPE. The study was very well performed and the patients were carefully screened and selected. The primary outcome of the study is really accurate, whereas the authors chose to combine both hospital death and the need for tracheal intubation in composite criteria. Secondary outcomes are also of importance, including the resolution time, myocardial infarction rate, and the hospital length of stay. Mortality rate was rather low in both groups $(\leq 5 \%)$, and the combined outcome parameter was similar between NIPPSV and CPAP. No difference in terms of myocardial infarction rate was observed within groups, thus confirming all previous data. NIPPSV was clearly associated with a shorter resolution time $(-50 \pm 19 \mathrm{~min})$.

Taking into account previous literature and the new data provided by Nouira et al. [30], what conclusions can be drawn from a clinical point of view? First, the use of NIV during acute respiratory distress is still an issue of importance. Even if outcome parameters improvement is not as important as it was during an initial period when nitrate boluses were not the standard of care [3, 17], such respiratory distress and dyspnea lessening should be all clinicians' first goal. Second, even if one considers that the final outcome parameters (mortality, length of stay) are equivalent while using either CPAP or NIPPSV, the shorter resolution time with NIPPSV associated with a more rapid $\mathrm{PaCO}_{2}$ decrease should favor its use when such a ventilatory mode is available.

However, the choice of ventilatory mode should also be based on factors such as the operation setting (prehospital, emergency, intensive care), the staff experience, and the devices' ergonomics. In an ICU setting, NIPPSV would probably be the best choice; the use of lightweight, cheap, and simple CPAP devices during the pre-hospital care could be considered a better one, especially due to volumetry constraint and to the low efficiency of pressure support modes from several emergency and transport ventilators. Within an emergency department that has modern ICU ventilators and experienced staff that are able to use them on a routine basis for intubated patients, the use of simple CPAP devices might not be as interesting as it will in another emergency unit environment with less experience on the topic. We should consider that on a routine basis, beside real differences in terms of physiological improvements between CPAP and NIPPSV, the choice of one ventilatory mode over another is based primarily on the physicians' expertise and the operation setting.

\section{References}

1. Poppas A, Rounds S (2002) Congestive heart failure. Am J Respir Crit Care Med 165:4-8
2. Mejhert M, Persson H, Edner M, Kahan $\mathrm{T}$ (2001) Epidemiology of heart failure in Sweden: a national survey. Eur $\mathbf{J}$ Heart Fail 3:97-103
3. L'Her E, Duquesne F, Girou E, de Rosière $\mathrm{X}$, Le Conte $\mathrm{P}$, Renault $\mathrm{S}$, Allamy JP, Boles JM (2004) Noninvasive continuous positive airway pressure in elderly cardiogenic pulmonary edema patients. Intensive Care Med 30:882-888 
4. Le Conte P, Coutant V, N'Guyen JM, Baron D, Touze MD, Potel G (1999) Prognostic factors in acute cardiogenic pulmonary edema. Am J Emerg Med 17:329-332

5. Nieminen MS, Böhm M, Cowie MR, Drexler H, Filippatos GS, Jondeau G, Hasin Y, Lopez-Sendon J, Mebazaa A, Metra M, Rhodes A, Swedberg K, Priori SG, Garcia MA, Blanc JJ, Budaj A, Cowie MR, Dean V, Deckers J, Burgos EF, Lekakis J, Lindahl B, Mazzotta G, Morais J, Oto A, Smiseth OA, Garcia MA, Dickstein K, Albuquerque A, Conthe P, CrespoLeiro M, Ferrari R, Follath F, Gavazzi A, Janssens U, Komajda M, Morais J, Moreno R, Singer M, Singh S, Tendera $\mathrm{M}$, Thygesen K, ESC Committee for Practice Guidelines (CPG) (2005) Executive summary of the guidelines on the diagnosis and treatment of acute heart failure: the task force on acute heart failure of the European Society of Cardiology. Eur Heart J 26:384-416

6. Troisième conférence de consensus commune (SFAR, SPLF, SRLF). Ventilation non invasive au cours de l'insuffisance respiratoire aiguë (nouveau-né exclu). http://www.splf. org/s/spip.php?article486

7. Masip J, Roque M, Sánchez B, Fernández R, Subirana M, Expósito JA (2005) Noninvasive ventilation in acute cardiogenic pulmonary edema: systematic review and meta-analysis. JAMA 294:3124-3130

8. Peter JV, Moran JL, Phillips-Hughes J, Graham P, Bersten AD (2006) Effect of non-invasive positive pressure ventilation (NIPPV) on mortality in patients with acute cardiogenic pulmonary oedema: a meta-analysis. Lancet 367:1155-1163

9. Collins SP, Mielniczuk LM, Whittingham HA, Boseley ME, Schramm DR, Storrow AB (2006) The use of noninvasive ventilation in emergency department patients with acute cardiogenic pulmonary edema: a systematic review. Ann Emerg Med 48:260-269

10. Winck JC, Azevedo LF, Costa-Pereira A, Antonelli M, Wyatt JC (2006) Efficacy and safety of non-invasive ventilation in the treatment of acute cardiogenic pulmonary edema-a systematic review and meta-analysis. Crit Care 10:R69

11. Sharp JT, Griffith GT, Bunnell IL, Greene DG (1958) Ventilatory mechanics in pulmonary oedema in man. J Clin Invest 37:111-117
12. Aubier M, Trippenbach T, Roussos C (1981) Respiratory muscle fatigue during cardiogenic shock. J Appl Physiol 51:499-508

13. Broseghini C, Brandolese R, Poggi R, Polese G, Manzin E, Milic-Emili J, Rossi A (1988) Respiratory mechanics during the first day of mechanical ventilation in patients with pulmonary oedema and chronic airway obstruction. Am Rev Respir Dis 138:355-361

14. Field S, Kelly SM, Macklem PT (1982) The oxygen cost of breathing in patients with cardiorespiratory disease. Am Rev Respir Dis 126:9-13

15. Buda AJ, Pinsky MR, Ingels NB Jr, Daughters GT 2nd, Stinson EB, Alderman EL (1979) Effect of intrathoracic pressure on left ventricular performance. N Engl J Med 301:453-459

16. Naughton MT, Rahman MA, Hara K, Floras JS, Bradley TD (1995) Effect of continuous positive airway pressure on intrathoracic and left ventricular transmural pressures in patients with congestive heart failure. Circulation 91:1725-1731

17. Bersten AD, Holt AW, Vedig AE, Skowronski GA, Baggely CJ (1991) Treatment of severe cardiogenic pulmonary edema with continuous positive airway pressure delivered by face mask. N Engl J Med 325:1825-1830

18. Perel A, Williamson DC, Modell JH (1983) Effectiveness of CPAP by mask for pulmonary oedema associated with hypercarbia. Intensive Care Med 9:17-19

19. Emerson H (1909) Artificial respiration in the treatment of edema of the lungs. Arch Intern Med 3:368-371

20. Poulton E, Oxon D (1936) Left-sided heart failure with pulmonary edema: its treatment with the "pulmonary plus pressure machine". Lancet 231:981-983

21. Barach A, Martin J, Eckman M (1938) Positive pressure respiration and its application to the treatment of acute pulmonary oedema. Ann Intern Med 12:754-795

22. Appendini L, Patessio A, Zanaboni S, Carone M, Gukov B, Donner CF, Rossi A (1994) Physiologic effects of positive end-expiratory pressure and mask pressure support during exacerbations of chronic obstructive pulmonary disease. Am J Respir Crit Care Med 149:1069-1076
23. L'Her E, Deye N, Lellouche F, Taille S, Demoule A, Fraticelli A, Mancebo J, Brochard L (2005) Physiologic effects of non-invasive ventilation during acute lung injury. Am J Respir Crit Care Med 172:1112-1118

24. Chadda K, Annane D, Hart N, Gajdos P, Raphael J, Lofaso F (2002) Cardiac and respiratory effects of continuous positive airway pressure and noninvasive ventilation in acute cardiac pulmonary oedema. Crit Care Med 30:2457-2461

25. Mehta S, Jay GD, Woolard RH, Hipona RA, Connolly EM, Cimini DM, Drinkwine JH, Hill NS (1997)

Randomized, prospective trial of bilevel versus continuous positive airway pressure in acute pulmonary edema. Crit Care Med 25:620-628

26. Bellone A, Monari A, Cortellaro F, Vettorello M, Arlati S, Coen D (2004) Myocardial infarction rate in acute pulmonary edema: noninvasive pressure support ventilation versus continuous positive airway pressure. Crit Care Med 32:1860-1865

27. Park M, Sangean MC, Volpe MS, Feltrim MIZ, Nozawa E, Leite PF, Amato MBP, Lorenzi-Filho G (2004) Randomized, prospective trial of oxygen, continuous positive airway pressure, and bilevel positive airway pressure by face mask in acute cardiogenic pulmonary edema. Crit Care Med 32:2407-2415

28. Moritz F, Brousse B, Gellée B, Chajara A, L'Her E, Hellot MF, Bénichou J (2007) Continuous positive airway pressure versus bilevel noninvasive ventilation in acute cardiogenic pulmonary edema: a randomized multicenter trial. Ann Emerg Med 50:666-675

29. Gray A, Goodacre S, Newby DE, Masson M, Sampson F, Nicholl J, 3CPO trialists (2008) Noninvasive ventilation in acute cardiogenic pulmonary edema. N Engl J Med 359:142-151

30. Nouira S, Boukef R, Bouida W, Kerkeni W, Beltaief K, Boubaker H, Boudhib L, Grissa M-H, Naceur Trimech M, Boussarsar H, Methamem M, Marghli S, Ltaief M (2010) Noninvasive pressure support ventilation and CPAP in cardiogenic pulmonary edema: a multicenter randomized study in emergency department. Intensive Care Med. doi: 10.1007/s00134-010-2082-3 